\title{
Epidemiological, clinical profile and outcome of multi-system inflammatory syndrome in children (MIS-C) admitted in government tertiary care hospital of Kanyakumari district
}

\author{
Steeve Gnana Samuel*, Suresh Placode Monikanta, Arul Prasath Subramoniam Vasudevan, \\ Nagalekshmi Rajamanickam
}

Department of Paediatrics, Kanyakumari Government Medical College, Tamil Nadu, India

Received: 31 August 2021

Revised: 30 September 2021

Accepted: 05 October 2021

\section{*Correspondence:}

Dr. Steeve Gnana Samuel,

E-mail: steevegnanasamuel@gmail.com

Copyright: (c) the author(s), publisher and licensee Medip Academy. This is an open-access article distributed under the terms of the Creative Commons Attribution Non-Commercial License, which permits unrestricted non-commercial use, distribution, and reproduction in any medium, provided the original work is properly cited.

\begin{abstract}
We report twelve children with a median age of 7 year (IQR 3years to 12 years) who fulfilled MIS-C WHO criteria. The male to female ratio was $2: 1$. Affected children had gastrointestinal symptoms (92\%), respiratory symptoms (67\%), cardiovascular symptoms (58\%), neurological symptoms (50\%), renal symptoms (33\%), followed by muco-cutaneous manifestations (25\%). $83 \%$ of children had lymphocytopenia. It was found that lymphocytopenia was directly correlated to disease severity. The majority of the children had elevated CRP, transaminase, and deranged coagulation profiles. All 4 systems were involved in 7 children (58\%). Intensive care treatment was required for all the cases (100\%). There were no deaths. Children with coronavirus disease 2019 (COVID-19) associated MIS-C can present with a wide range of signs and symptoms. They can deteriorate quickly and hence a high index of suspicion; early referral and early initiation of treatment with steroids and IVIg can save the lives of children with MIS-C.
\end{abstract}

Keywords: Multi-system inflammatory syndrome in children, Lymphocytopenia, COVID-19, IVIG, Methylprednisolone

\section{INTRODUCTION}

Coronavirus disease 2019 (COVID-19) Pandemic has created many challenges in the world. Initially, it was thought that children affected with COVID-19 were asymptomatic or had a mild illness. ${ }^{1,2}$ But around 2 to 6 weeks after the peak of COVID-19, children started to show delayed immune activation to the COVID-19 virus and began showing signs of multi-systemic inflammation. ${ }^{3}$

The pathogenesis of MIS-C includes viral mimicry of the host antigen resulting in auto-antibody, $\mathrm{T}$ cell recognition of viral antigen expressed on infected cell, formation of immune complex activating inflammation, viral superantigens activating host immune cell triggering $\mathrm{T}$ cells to produce massive cytokines like IL1 and causing multi-system damage. ${ }^{4}$

World Health Organization (WHO) has developed a preliminary case definition and case report form for multisystem inflammatory disorder in children and adolescents. The preliminary case definition reflects the clinical and laboratory features observed in children reported to date and serves to identify suspected or confirmed cases both to provide treatment and for provisional reporting and surveillance. ${ }^{5}$

\section{Preliminary case definition}

Children and adolescents $0-19$ years of age with fever $\geq 3$ days with any two out of five features listed such as Rash 
with or without bilateral non-purulent conjunctivitis or mucocutaneous inflammation signs (oral, hands or feet), Hypotension or shock, features of myocardial dysfunction, pericarditis, valvulitis, or coronary abnormalities (including ECHO findings or elevated Troponin/NTproBNP), evidence of coagulopathy (by PT, PTT, elevated d-Dimers) or acute gastrointestinal problems (diarrhoea, vomiting, or abdominal pain) along with elevated markers of inflammation such as ESR, C-reactive protein, or procalcitonin with no other obvious microbial cause of inflammation, including bacterial sepsis, staphylococcal or streptococcal shock syndromes and with evidence of COVID-19 (RT-PCR, antigen test or serology positive), or likely contact with patients with COVID-19.5

\section{CASE SERIES}

This cases was collected in the department of pediatrics at Government tertiary care hospital in Kanyakumari district between June 2021 and July 2021. Inclusion criteria: All children aged from 1 month to 12 years who fulfilled WHO criteria of MIS-C case definition. Exclusion criteria: Children who did not fulfil MISC criteria were excluded from the study.

The symptoms of the children were classified as follows:

Table 1: Common Symptoms encountered in children with COVID-19.

\begin{tabular}{|c|c|}
\hline System & Symptoms \\
\hline Cardiac & $\begin{array}{l}\text { Shock } \\
\text { Myocarditis } \\
\text { Valvular insufficiency } \\
\text { Heart failure } \\
\text { Coronary artery abnormality }\end{array}$ \\
\hline Respiratory & $\begin{array}{l}\text { Nasal drip/ congestion } \\
\text { Pharyngodynia/ Pharyngitis } \\
\text { Cough } \\
\text { Throat pain } \\
\text { Respiratory distress } \\
\text { Acute respiratory failure }\end{array}$ \\
\hline $\begin{array}{l}\text { Gastrointesti } \\
\text { nal }\end{array}$ & $\begin{array}{l}\text { Abdomen pain } \\
\text { Diarrhoea } \\
\text { Nausea/ vomiting }\end{array}$ \\
\hline Renal & $\begin{array}{l}\text { Renal failure } \\
\text { Oliguria/ Anuria } \\
\text { Oedema }\end{array}$ \\
\hline $\begin{array}{l}\text { Skin \& } \\
\text { Mucous } \\
\text { membrane }\end{array}$ & $\begin{array}{l}\text { Polymorphous rash/ perineal } \\
\text { erythema } \\
\text { Erythema of palms \& Soles } \\
\text { Strawberry tongue/ Cracked lips } \\
\text { Non-exudative conjunctival } \\
\text { congestion } \\
\text { Lymph node enlargement }\end{array}$ \\
\hline CNS & $\begin{array}{l}\text { Meningoencephalitis } \\
\text { Irritability } \\
\text { Confusion } \\
\text { Seizures }\end{array}$ \\
\hline
\end{tabular}

All children were included in this study after obtaining the informed consent of the caretaker.

A total of 12 children with a median (IQR) age of 7 years who fulfilled the MIS-C criteria in June, July 2021 was analyzed. The results showed male to female ratio of children affected was $2 .: 1.4$ children $(33 \%)$ were less than 6 years. Out of 12 children, 11 children (92\%) had COVID SARS COV-2 positive serological assay and one child (8\%) was RT PCR throat swab positive.

Table 2: Demography and COVID 19 status in children with MISC.

\begin{tabular}{|lll|}
\hline Parameters & All children & Percentage \\
\hline Age - Median & 7 & \\
\hline Male & $8 / 12$ & 67 \\
\hline Female & $4 / 12$ & 33 \\
\hline Male: Female & $2: 1$ & \\
\hline Comorbidity & $0 / 12$ & 0 \\
\hline Serology positive & $11 / 12$ & 92 \\
\hline RT-PCR positive & $1 / 12$ & 8 \\
\hline Fever & $12 / 12$ & 100 \\
\hline
\end{tabular}

All children (100\%) required PICU admission. Among the children analyzed, 11 children (92\%) had GI symptoms; respiratory symptoms were present in 8 children $(67 \%)$, CVS symptom present in 7 children (58\%), the neurological symptom was present in 6 children $(50 \%)$, the renal system was involved in 4 children (33\%) followed by mucocutaneous symptom involvement in 3 children (25\%). On analyzing the Chest radiography of 12 children, 9 children $(55 \%)$ had positive findings. USG abdomen showed features suggestive of hepatomegaly, ascites and pleural effusion in 6 children $(50 \%)$. Two children $(17 \%)$ had ECHO suggestive of Myocarditis. The mean length of hospital stay was 14 days. There was no mortality.

On analyzing the lab parameters, $83 \%$ of children had lymphocytopenia, and $75 \%$ had leukocytosis. It was found that lymphocytopenia was directly correlated with disease severity. $75 \%$ of children had elevated CRP, transaminase and deranged coagulation profile, $67 \%$ had elevated ESR and hypoalbuminemia, and $33 \%$ had hyponatremia. $67 \%$ of children had High ferritin, 58\% had elevated LDH and $42 \%$ had elevated triglycerides. $75 \%$ of children had elevated D-Dimer, $17 \%$ of children had elevated troponin and Pro-BNP. $42 \%$ of children had anaemia, and $25 \%$ of children had thrombocytopenia. $75 \%$ of children had abnormal X-ray, and $17 \%$ of children had abnormal ECHO. All 4 systems were involved in 7 children $(58 \%)$.

Intensive care treatment was required for all the cases $(100 \%)$. Out of 12 children, 6 cases $(50 \%)$ needed oxygen support via nasal cannula, 3 cases $(25 \%)$ required noninvasive mechanical ventilation, 2 cases $(17 \%)$ required CPAP ventilation and 1 case $(8 \%)$ required mechanical ventilator support. 
Table 3: Clinical features of children with MISC.

\begin{tabular}{|lll|}
\hline Parameters & All children & Percentage \\
\hline GI symptoms & $11 / 12$ & 92 \\
\hline Abdomen pain & $9 / 12$ & 75 \\
\hline Vomiting & $5 / 12$ & 42 \\
\hline Diarrhoea & $3 / 12$ & 25 \\
\hline Rectal bleeding & $1 / 12$ & 8 \\
\hline Muco-cutaneous symptoms & $3 / 12$ & 25 \\
\hline Lymphadenopathy & $2 / 12$ & 17 \\
\hline Rash & $3 / 12$ & 25 \\
\hline Oedema & $3 / 12$ & 25 \\
\hline Conjunctival congestion & $2 / 12$ & 17 \\
\hline Oral mucosa involvement & $1 / 12$ & 8 \\
\hline CVS symptoms & $7 / 12$ & 58 \\
\hline Shock & $7 / 12$ & 58 \\
\hline Myocarditis & $2 / 12$ & 17 \\
\hline Heart failure & $1 / 12$ & 8 \\
\hline Coronary artery abnormality & $0 / 12$ & 0 \\
\hline Renal Symptoms & $4 / 12$ & 33 \\
\hline Renal failure & $1 / 12$ & 8 \\
\hline Oliguria & $4 / 12$ & 33 \\
\hline Respiratory symptoms & $8 / 12$ & 67 \\
\hline Nasal drip/Congestion & $4 / 12$ & 33 \\
\hline Pharyngitis & $3 / 12$ & 25 \\
\hline Cough & $5 / 12$ & 42 \\
\hline Throat pain & $2 / 12$ & 17 \\
\hline Respiratory distress & $2 / 12$ & 17 \\
\hline Acute respiratory failure & $2 / 12$ & 17 \\
\hline Neurological symptoms & $6 / 12$ & 50 \\
\hline Meningo-encephalitis & $1 / 12$ & 8 \\
\hline Irritability & $6 / 12$ & 50 \\
\hline Confusion & $6 / 12$ & 50 \\
\hline Seizures & $1 / 12$ & 8 \\
\hline Four Systems involved & $7 / 12$ & 58 \\
\hline & & \\
\hline
\end{tabular}

Table 4: Treatment and outcomes of children with MISC.

\begin{tabular}{|lll|}
\hline Parameters & All children & Percentage \\
\hline PICU admission & $12 / 12$ & 100 \\
\hline Mechanical ventilation & $1 / 12$ & 8 \\
\hline NIMV & $3 / 12$ & 25 \\
\hline CPAP & $2 / 12$ & 17 \\
\hline O2 via nasal cannula & $6 / 12$ & 50 \\
\hline Fluid bolus & $7 / 12$ & 58 \\
\hline Vasoactive support & $1 / 12$ & 8 \\
\hline IVIg used & $3 / 12$ & 25 \\
\hline Steroid used & $9 / 12$ & 75 \\
\hline Aspirin used & $4 / 12$ & 33 \\
\hline LMWH used & $4 / 12$ & 33 \\
\hline
\end{tabular}


Out of 12 cases, 9 cases $(75 \%)$ were treated with steroids alone, 4 children (33\%) were treated with LMWH followed by aspirin and 3 children (25\%) received IV immunoglobulin along with steroids. All children (100\%) received broad-spectrum antibiotics at presentation and were stopped with negative culture reports. No organisms were isolated from the blood cultures.

Table 5: Imaging and mean duration of hospital stay in children with MISC.

\begin{tabular}{|lll|}
\hline Parameters & All children & Percentage \\
\hline Abnormal X-ray & $9 / 12$ & 75 \\
\hline Abnormal ECHO & $2 / 12$ & 17 \\
\hline $\begin{array}{l}\text { Abnormal USG } \\
\text { abdomen }\end{array}$ & $6 / 12$ & 50 \\
\hline Mortality & $0 / 12$ & 0 \\
\hline $\begin{array}{l}\text { Mean duration of } \\
\text { hospital stay }\end{array}$ & 14 days & \\
\hline
\end{tabular}

\section{DISCUSSION}

This study was intended to know the epidemiological profile, clinical features and outcome of children with MIS-C. It was found that even if most of the children were asymptomatic, some developed an inflammatory state, as seen in this study. The fact Is supported by the systematic review by Yasuhara et al who found that children with COVID-19 are generally less severe or asymptomatic. ${ }^{6}$ Early detection of children with mild symptoms or an asymptomatic state and early diagnosis of MIS-C is mandatory for the management of COVID-19 and the prevention of transmission and a severe inflammatory state.

In our study, we found out the GI symptoms were more common (91\%), followed by respiratory symptoms (64\%), followed by CVS symptoms (55\%), neurological symptoms (45\%), renal symptoms $(36 \%)$, followed by mucocutaneous involvement $(27 \%)$. In a study conducted by Radia et al patients with MIS-C were noted to have a high frequency of gastrointestinal symptoms (71\%), including abdominal pain $(34 \%)$ and diarrhoea $(27 \%){ }^{7}$ Cough and respiratory distress were reported in $4.5 \%$ and $9.6 \%$ cases, respectively.

In a study conducted by Dhanalakshmi et al, 19 children with a median age of 6 years (IQR: 13 months-16 years) presented with fever. Multi-organ involvement (79\%), mucocutaneous involvement $(74 \%)$, cardiovascular symptoms $(63 \%)$, and gastrointestinal symptoms (42\%) were the other features. ${ }^{8}$ Elevated C-reactive protein levels were found in all of them. The majority of them had evidence of coagulopathy; intensive care admissions were needed in $12(63 \%)$, and vasoactive medications were given to $6(31.5 \%)$ children. There were no deaths.
In our study, we found out that lymphocytopenia was directly correlated with disease severity. In a study conducted by Terpos et al, Lymphopenia on admission (defined as lymphocyte count $\leq 1,100$ cells/ $\mu$ l) are associated with a three-fold risk of poor outcome younger as compared to older patients. ${ }^{9}$ In a study conducted by Huang et al, Lymphocyte counts were lower in patients with ARDS, severe disease requiring ICU care, and in nonsurvivors. ${ }^{10}$

Our study had $18 \%$ of children with low EF, but none had coronary artery abnormality. $82 \%$ of children required steroids, and $18 \%$ of children needed immunoglobulin. All children had increased inflammatory markers and were monitored closely. In a study conducted by Patnaik et al fever was the most common presentation, found in 18 $(85.7 \%)$ patients. ${ }^{11}$ All had a marked hyper-inflammatory state. Low ejection fraction (EF) was found in 10 (47.6\%), but none had any coronary artery abnormality. All received corticosteroids, while $7(33.3 \%)$ children required additional treatment with intravenous Immunoglobulins.

\section{CONCLUSION}

Children with COVID-19 associated with MIS-C can present with a wide range of signs and symptoms. They can deteriorate quickly and hence a high index of suspicion. Early referral and early initiation of treatment with steroids and IVIg can save the life of children with MIS-C.

\section{Funding: No funding sources \\ Conflict of interest: None declared \\ Ethical approval: Not required}

\section{REFERENCES}

1. Liu W, Zhang QI, Chen J, Xiang R, Song H, Shu S, et al. Detection of Covid-19 in children in early January 2020 in Wuhan, China. New England Journal of Medicine. 2020;382(14):1370-1.

2. Lu X, Zhang L, Du H, Zhang J, Li YY, Qu J, et al. Chinese Pediatric Novel Coronavirus Study Team. SARS-CoV-2 Infection in Children. N Engl J Med. 2020;382(17):1663-5.

3. García LF. Immune response, inflammation, and the clinical spectrum of COVID-19. Frontiers in immunology. 2020;11:1441.

4. Nakra NA, Blumberg DA, Herrera-Guerra A, Lakshminrusimha S. Multi-System Inflammatory Syndrome in Children (MIS-C) Following SARSCoV-2 Infection: Review of Clinical Presentation, Hypothetical Pathogenesis, and Proposed Management. Children (Basel). 2020;7(7):69.

5. Pawar MS. Multi system inflammatory syndrome in children and adolescents temporally related to COVID-19. Int J Multidiscip Res. 2020;1(1):97-102.

6. Yasuhara J, Kuno T, Takagi H, Sumitomo N. Clinical characteristics of COVID-19 in children: A 
systematic review. Pediatr Pulmonol. 2020;55(10):2565-75.

7. Radia T, Williams N, Agrawal P, Harman K, Weale $\mathrm{J}$, Cook $\mathrm{J}$, et al. Multi-system inflammatory syndrome in children \& adolescents (MIS-C): A systematic review of clinical features and presentation. Paediatr Respir Rev. 2021;38:51-7.

8. Dhanalakshmi K, Venkataraman A, Balasubramanian S, Madhusudan M, Amperayani S, Putilibai S, et al. Epidemiological and Clinical Profile of Pediatric Inflammatory Multisystem Syndrome - Temporally Associated with SARSCoV-2 (PIMS-TS) in Indian Children. Indian Pediatr. 2020;57(11):1010-1014.

9. Terpos E, Ntanasis-Stathopoulos I, Elalamy I, Kastritis E, Sergentanis TN, Politou M, et al. Hematological findings and complications of COVID-19. Amer J Hematol. 2020;95:834-47.
10. Huang I, Pranata R. Lymphopenia in severe coronavirus disease-2019 (COVID-19): systematic review and meta-analysis. Journal of Intensive Care. 2020;8(1).

11. Patnaik S, Jain MK, Ahmed S, Dash AK, Sahoo B, Mishra R et al. Short-term outcomes in children recovered from multisystem inflammatory syndrome associated with SARS-CoV-2 infection. Rheumatology international. 2021;1-6.

Cite this article as: Samuel SG, Monikanta SP,

Vasudevan APS, Rajamanickam N. Epidemiological, clinical profile and outcome of multi-system inflammatory syndrome in children (MIS-C) admitted in government tertiary care hospital of Kanyakumari district. Int J Contemp Pediatr 2021;8:1879-83. 